\title{
Serum levels of anti-myelin antibodies in relapsing-remitting multiple sclerosis patients during different phases of disease activity and immunomodulatory therapy
}

\author{
Francesco Angelucci, Massimiliano Mirabella, Giovanni Frisullo, Marcella Caggiula, \\ Pietro Attilio Tonali and Anna Paola Batocchi* \\ Institute of Neurology, Department of Neuroscience, Catholic University, Largo Gemelli 8, 00168, Rome, Italy
}

\begin{abstract}
Antibodies against myelin oligodendrocyte antigens have been found in the immunoreactive brain lesions of Multiple Sclerosis (MS) patients. Recently it has been proposed that these antibodies can be used as a prognostic marker in the course of disease. However, the serum levels of these autoantibodies during different phases of disease activity or after an immunomodulatory therapy have been poorly investigated. In this study the serum levels of anti-myelin oligodendrocyte glycoprotein (MOG) (directed against the epitopes 1-26 and 15-40) and anti-myelin basic protein (MBP) antibodies were sequentially measured in the same MS patient either in relapse or remission phases. We found that MS patients in the relapse phase had higher serum anti-MOG (peptides 1-26 and 15-40) and anti-MBP antibody levels than controls. In addition, the levels of anti-MOG 1-26 were also elevated during the relapse as compared with the remission phase but no significant changes were found in the levels of anti-MOG 15-40 of anti-MBP antibodies. We also evaluated the effect of interferon-beta $(\beta)$ therapy on anti-myelin antibodies. 1-year of interferon- $\beta$ treatment did not induce any changes in the levels of anti-MOG and anti-MBP antibodies. In conclusion, these data indicate that the use of peripheral levels of autoantibodies against MOG and MBP as marker of multiple sclerosis might be complicated by the phase of disease activity and by the epitope of the MOG protein used.
\end{abstract}

Keywords: MOG, MBP, multiple sclerosis, relapse, remission, antibodies

\section{Introduction}

Multiple Sclerosis (MS) is a chronic inflammatory disease of the central nervous system (CNS), characterized by infiltration of macrophages and lymphocytes into the CNS and subsequent immunologic destruction of myelin sheath. Pathophysiological studies in humans [12] and animal model [17] of the disease (the experimental autoimmune encephalomyelitis, EAE) underline mainly a T-cell basis for the induction of inflam-

*Corresponding author: Anna Paola Batocchi, Institute of Neurology, Catholic University, Largo Gemelli 8, 00168, Rome, Italy. Tel.: +39 6 30154435; Fax: +39 6 35501909; E-mail: annapaola. batocchi@rm.unicatt.it. matory process and the formation of sclerotic plaques. However, there is also evidence of a humoral immune activity in MS [27] because antibodies against myelin oligodendrocyte antigens have been found in the sites of lesion [23]. Several myelin-type proteins with specific antigenic epitopes are thought to be involved in myelin destruction. These include myelin basic protein (MBP), proteo-lipid protein (PLP), and myelin oligodendrocyte glycoprotein (MOG) [9].

Many studies report detectable levels of MBP autoantibodies $[6,10]$ though other studies, using similar techniques, report their absence $[3,15,41]$. Similarly, the data regarding the detection of autoantibodies to MBP in the cerebrospinal fluid (CSF) of patients with MS vary widely [25]. 
MOG is a minor component of myelin proteins [31] that is restricted to the CNS $[2,5,19,24]$ and was identified as a candidate autoantigen in MS following the demonstration that MOG-induced EAE reproduced the immunopathology and clinical course of the human disease in rodents and primates [22,32,35]. MOG is located in the outermost region of the myelin sheath [5, 29,40 ] where it can be targeted by demyelinating autoantibody responses directed against its extracellular N-terminal Ig-like domain (amino acids 1-132) [28,36, 37]. A previous study has claimed that the most frequently recognised amino acid sequences are 1-26 and 63-87 in MS patients and 14-39 and 63-87 in healthy controls [14]. This concept was additionally supported by findings showing the presence of MOG-reactive antibodies associated with disintegrating vesicular myelin debris in acute demyelinating MS lesions [20,29]. A recent report also showed that MOG-antibodies can be used as a prognostic marker early in the course of disease [13].

Despite these evidences, it is not clear whether the presence of these antibodies points unequivocally to multiple sclerosis. In animal models, in contrast to what has been observed in major myelin protein knockout models [33], $\mathrm{MOG}^{-/-}$mice do not show any neurological symptom, and they have a normal life span and reproduction rate, suggesting that MOG is not essential in promoting and/or regulating the formation and maintenance of myelinated axons. Other studies in human have shown that elevated titers of these antibodies in serum and cerebrospinal fluid (CSF) can also occur in various neurological diseases, including non - immune-mediated disorders [1,11,38,39]. Moreover, many complicating aspects and issues in MS are still emerging. For example, it has been demonstrated that autoimmune reactions are not necessarily always detrimental; they may have benefits as well $[8,16,26$, 30].

These observations have raised a strong debate on the role of these antibodies in the pathogenesis and clinical course of MS. Interestingly, the relapsing-remitting (RR) course of MS is characterized by the switch from a phase of autoimmune activation to a phase of remission. This form of the disease has provided a model for investigating the role of these antibodies in the processes of autoimmune activation but the results of these studies were not consistent [23,34]. One possible explanation could be that since MS patients are characterized by a wide range of degree of autoimmune inflammation the selection of the appropriate and comparable experimental groups (either in relapse or remis- sion) could be difficult. To avoid this problem we measured the serum levels of anti-MOG (directed against the epitopes 1-26 and 15-40) and anti-MBP antibodies in the same MS patient and evaluated whether the acute and the stable phase of disease are characterized by different titers of these antibodies. Moreover, to elucidate the question of whether myelin antibodies are deleterious or play a defensive role in MS, we tested the hypothesis that interferon-beta $(\beta)$ treatment induces significant changes in the circulating levels of these autoantibodies.

\section{Materials and methods}

\subsection{Patients}

Levels of anti-MOG and anti-MBP antibodies were determined in serum samples from $40 \mathrm{MS}$ patients, both in relapse and in remission phase of disease, and 47 healthy controls. $33 \mathrm{MS}$ patients started interferon- $\beta$ treatment and were also tested before and after 2, 6 and 12 months of therapy.

The patients underwent clinical examination and brain and spinal cord magnetic resonance imaging (MRI) in remission phase and at time of relapse. MRI data were acquired with high resolution 1.5 Tesla system (5-mm slice thickness). Scanning sessions included proton density (echo time [TE] 20/repetition time [TR] 2500), T2-weighted (TE 80/TR 2500) and T1-weighted (TE 17/TR 600) images. The T1-weighted images were acquired before and 10 minutes after an intravenous injection of gadolinium-diethylenetriaminepentaacetic acid $(0.1 \mathrm{mmol} / \mathrm{kg})(\mathrm{Gd}-\mathrm{DTPA})$. Disease activity was evaluated by clinical examination and MRI. Patients were considered in relapse phase when they showed an episode of new neurological disturbance lasting at least 24 hours and/or Gd-DTPA enhancing lesions at MRI; in stable phase, when they had shown neither new neurological symptom nor enhancing lesions for three months [21]. Disability degree was assessed with the Expanded Disability Status Scale (EDSS). Informations about age, sex, clinical assessment of patients are shown in Table 1.

The study was approved by the Ethical Committee of our institution. Informed consent was obtained from all subjects volunteering for this study. 


\begin{tabular}{cccccc}
\multicolumn{7}{c}{ Table 1 } \\
Patients & Age & Clinical features of RRMS patients & \\
& $\begin{array}{c}\text { Sex } \\
\text { (years) }\end{array}$ & $\begin{array}{c}\text { Disease duration } \\
\text { (male/female) }\end{array}$ & $\begin{array}{c}\text { (years) } \\
\text { Annual relapse rate }\end{array}$ & EDSS \\
40 & $28.8 \pm 9.08$ & $9 \mathrm{M} / 31 \mathrm{~F}$ & $5.25 \pm 6.09$ & $1.5 \pm 0.7$ & $1.66 \pm 1.54$
\end{tabular}

Notes: Data are the mean \pm SD. EDSS $=$ Expanded Disability Status Scale; $M=$ male; $F=$ female.

Serum levels of anti-MOG antibodies in relapsing-remitting MS

patients and controls
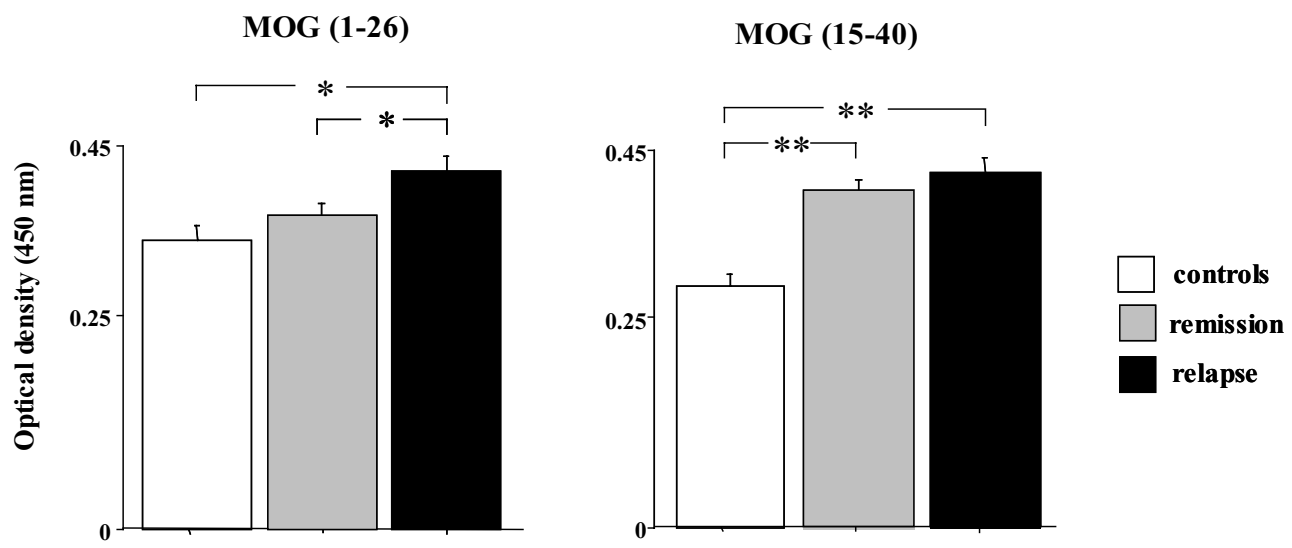

Fig. 1. Levels of antibodies against MOG (sequences 1-26 or 15-40) obtained from MS patients in relapse and remission phases and controls. Data are the mean $\pm \mathrm{SEM}$. Asterisks indicate statistical significances. ${ }^{*} p<0.05,{ }^{* *} p<0.01$.

\subsection{Antigens}

Human MOG peptides, selected in the immunoglobulin-like domain of the MOG molecule, were synthesized and HPLC purified (more than $95 \%$ purity) by INBIOS (INBIOS srl, Italy). The specific peptide sequences is GQFRVIGPRHPIRALVGDEVELPCRI corresponding to sequence 1-26 and LVGDEVELPCRISPGKNATGMEVGWY corresponding to sequence 15-40. Human MBP was purchased from Chemicon (CHEMICON Int., USA).

\subsection{Blood sampling}

Venous blood was collected in MS patients into sampling tubes. Samples were centrifuged within $20 \mathrm{~min}$ following sampling at $2000 \times \mathrm{g}$ for $20 \mathrm{~min}$. Serum was then aliquoted and stored at $-80^{\circ} \mathrm{C}$ until assaying.

\subsection{Antibody determination}

Serum samples were tested for levels of anti-MOG and anti-MBP antibodies by a modified enzyme-linked immunosorbent assay, as previously reported by oth- ers [30]. Briefly, 96-well microtiter plates (NuncImmuno plates; Nunc Als, Roskilde, Denmark) were coated with $100 \mu \mathrm{L}$ of a $10-\mu \mathrm{g} / \mathrm{mL}$ antigen (recombinant human MOG peptides or MBP) solution in phosphate-buffered saline solution (PBS), $\mathrm{pH} 7.4$, overnight at $4{ }^{\circ} \mathrm{C}$. Non-reactive sites were saturated with PBS with $1 \%$ bovine serum albumin [BSA] $(200 \mu \mathrm{L})$ for 2 hours at room temperature. A $100-\mu \mathrm{L}$ volume of plasma (diluted 1:5 diluted 1:200 in PBS with 1\% BSA and $0.05 \%$ Tween-20) was added to each well, and the plates were kept at room temperature for 1 hour. After washing, goat biotinylated antihuman IgG anti-Fab (100 $\mu \mathrm{L})$, diluted 1:4000 in PBS and 3\% BSA were added to each well of the tested plasma samples, and the plates were incubated for an additional 2 hours at room temperature. The plates were washed again, then peroxidase $(100 \mu \mathrm{L})$ that was conjugated to streptavidin and diluted 1:2000 in PBS and 1\% BSA was added to each well, and the plates were incubated for $30 \mathrm{~min}$ utes at $37^{\circ} \mathrm{C}$. Afterward, all plates were washed and a 3,3',5,5'-tetramethylbenzidine (TMB; Sigma-Aldrich Corp, St Louis, Mo) liquid substrate was added. The developing colour was stopped with $100 \mu \mathrm{L} \mathrm{HCl} 1$ M and read as an optical density at $405 \mathrm{~nm}\left(\mathrm{OD}_{405}\right)$. Each 


\section{Serum levels of anti-MBP antibodies in relapsing-remitting MS patients and controls}

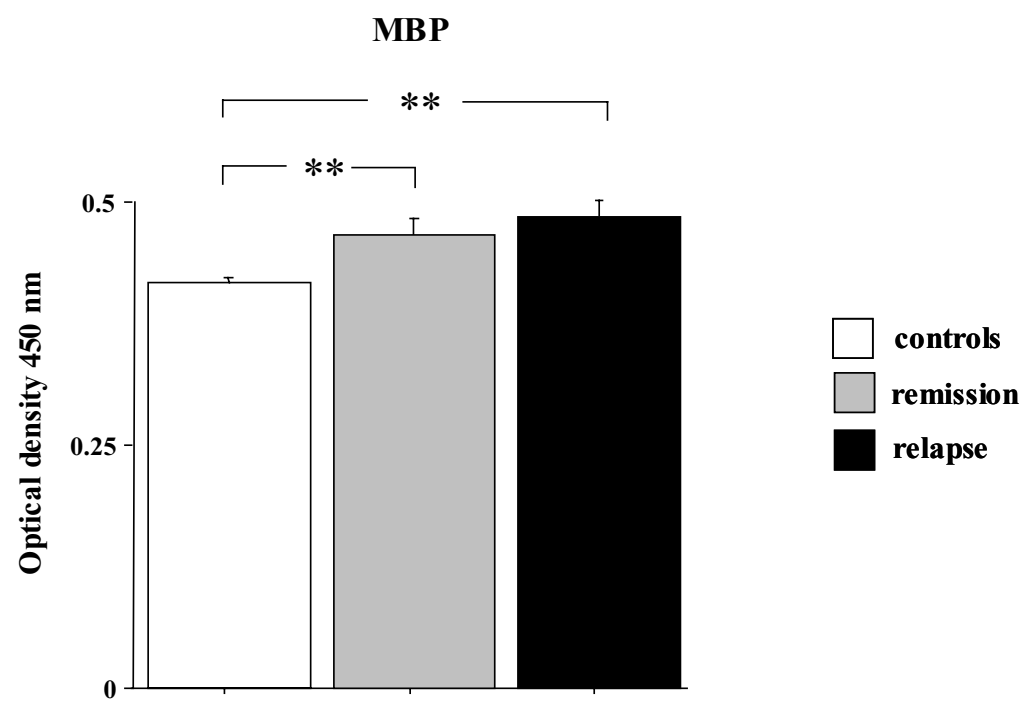

Fig. 2. Levels of antibodies against MBP obtained from MS patients in relapse and remission phases and controls. Data are the mean \pm SEM. Asterisks indicate statistical significances. ${ }^{* *} p<0.01$.

plasma sample was tested in duplicate, so the results for every specimen express the average value of the OD readings. The within-assay variation was less than $15 \%$. Specimens were considered positive if their average OD reading was higher than the mean $\mathrm{OD}_{405}$ level +2 standard deviations (SDs) of controls.

\subsection{Statistical analysis}

Differences in variables between MS patients and healthy subjects were tested by analysis of variance (ANOVA) and comparisons between values obtained from the same patients in different phase of disease (relapse vs remission) or time of interferon- $\beta$ treatment (baseline vs 2-, 6-, 12-months) were performed by using the paired test (all values were normally distributed). Results are expressed as mean \pm SE. Pvalues $=0.05$ were considered statistically significant.

\section{Results}

\subsection{Levels of anti-MOG and anti-MBP antibodies measured in the same MS patients at different phases of disease (relapse vs remission)}

We found that levels of anti-MOG 1-26 (Fig. 1) were significantly higher in MS patients in relapse phase than

\section{Table 2}

Number of patients positive for autoantibodies against the myelin proteins MOG and MBP

$\begin{array}{lccc} & \text { Anti-MBP } & \begin{array}{c}\text { Anti-MOG } \\ (1-26)\end{array} & \begin{array}{c}\text { Anti-MOG } \\ (15-40)\end{array} \\ \text { Relapse } & 18 / 40^{* *} & 0 / 40 & 9 / 40^{*} \\ \text { Remission } & 16 / 40^{* *} & 0 / 40 & 8 / 40^{*} \\ \text { Controls } & 0 / 47 & 3 / 47 & 0 / 47\end{array}$

Notes: Values are the numbers of positive patients/total number of patients. Patients were considered positive to autoantibodies if their average OD reading was higher than the mean $\mathrm{OD}_{405}$ level +2 standard deviations of controls. ${ }^{*} p<0.01,{ }^{* *} p<0.001$, as measured with Fisher's exact P-value vs controls.

in remission $(p<0.05)$. There were no significant differences in anti-MOG 15-40 (Fig. 1) and anti-MBP (Fig. 2) antibody levels between relapse and remission phases.

\subsection{Levels of anti-MOG and anti-MBP antibodies in serum from relapsing-remitting $M S$ patients versus controls}

Levels of anti-MOG 1-26 antibodies of MS patients in relapse phase were significantly higher than controls $(p<0.05)$ (Fig. 1). The levels of anti-MOG 15-40 (Fig. 1) and anti-MBP (Fig. 2) antibodies were elevated in MS patients both in relapse ( $p$ 's $<0.01)$ and remission $(p$ 's $<0.01)$ phases as compared with controls. 


\section{Effects of interferon- $\beta$ on anti-MOG and anti- MBP serum levels}
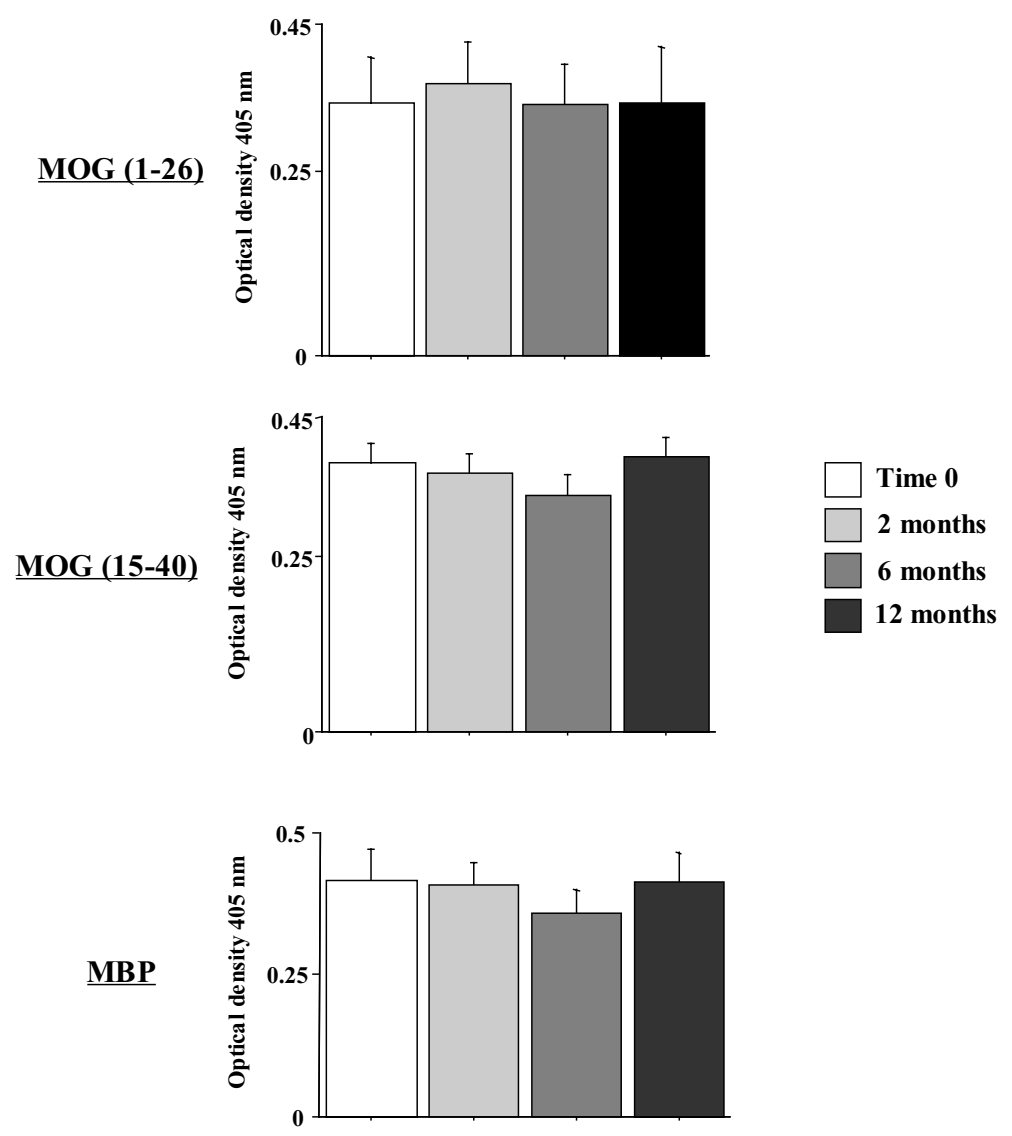

Fig. 3. Levels of antibodies against MOG (sequences 1-26 or 15-40) and MBP at baseline and after 2, 6, and 12 months of interferon- $\beta$ treatment in RRMS patients. Data are the mean \pm SEM.

\subsection{Frequency of patients who were positive for the anti-MOG antibodies and the anti-MBP antibody}

The cut-off value above which patients were considered positive for antibodies was set as the mean value for controls +2 SDs: $0.563 \mathrm{OD}_{405}$ for the anti-MOG 1-26 antibody, $0.481 \mathrm{OD}_{405}$ for the anti-MOG 15-40 antibody, and $0.516 \mathrm{OD}_{405}$ for the anti-MBP antibody. As shown in Table 2, in MS patients (both in relapse and remission phases) the frequency of positive values for the anti-MOG antibody 15-40 and the anti-MBP antibody was significantly higher as compared to controls ( $p$ 's $>0.05)$. There were no significant differences in percentage of anti-MOG 1-26 positive values between relapsing-remitting MS patients and controls.

\subsection{Effects of interferon- $\beta$ on anti-MOG and anti-MBP serum levels}

In 33 patients we measured the levels of anti-MOG and anti-MBP antibodies at baseline and after 2, 6, and 12 months of treatment with interferon- $\beta$. As shown in Fig. 3, there were no differences between the levels of these autoantibodies measured before and after interferon- $\beta$ treatment.

\section{Discussion}

This study demonstrates that MS patients in the relapse phase had higher serum anti-MOG (peptides 1-26 and 15-40) and anti-MBP antibody levels than healthy subjects. In addition, the levels of anti-MOG 1-26 
were also elevated during relapse as compared with the remission phase. We also observed that 1-year of interferon- $\beta$ treatment did not induce any changes in the levels of anti-MOG and anti-MBP antibodies.

The peculiarity of this study was the measurement of anti-MOG and anti-MBP antibodies serum levels in the same MS patient during the relapse and remission phases. Our data suggest that increased level of the antibody against the epitope 1-26, rather than the epitope 15-40, of MOG protein is a potential marker of the relapse phase. This finding might be explained by the three-dimensional structure of the MOG extracellular domain $[7,18]$. It is possible that one antibody against a specific peptide sequence is directly involved in myelin damage while the presence of antibodies against other regions of the MOG protein may represent a secondary phenomenon not necessarily related to the disease.

Another important question is whether these autoantibodies are relevant as diagnostic tool for MS, as recently suggested [3]. However, our data failed to demonstrate a specific association between MS and serum levels of anti-MOG 1-26 antibodies. The serum levels of anti-MOG 1-26 antibodies of MS patients were usually not higher than the cut-off value for controls. Instead the percentage of anti-MOG 15-40 and anti-MBP-positive patients was significantly higher in MS patients as compared with the frequency in healthy subjects. These data are not consistent with those reported in a previous study [13]. However, it should be stressed that these analyses conducted cumulating large cohorts of patients have mostly generated conflicting results and the frequency of positive values can also be influenced by the sensitivity of the method used.

These findings uphold the question of whether these antibodies are deleterious or play a defensive role against further autoimmune attack after myelin breakdown [4]. In order to elucidate this question we followed over 1-year period 33 patients treated with interferon- $\beta$ (a disease modulating drug) and investigated whether this drug significantly alters the serum levels of the myelin autoantibodies. Our data showed that interferon- $\beta$ did not induce any changes of antiMOG and anti-MBP antibodies. These data however do not exclude the possibility that interferon- $\beta$, by reducing blood brain barrier access of these antibodies may produce beneficial effects.

\section{Conclusion}

In conclusion, our results indicate that antibodies directed against different epitopes of anti- MOG may produce conflicting results. While anti-MOG 15-40 and anti-MBP antibodies may serve as a diagnostic tool for MS versus healthy subjects, anti-MOG 1-26 antibodies may be useful in determining a relapse versus a remission phase.

\section{References}

[1] P. Amiguet, M.V. Gardinier, J.P. Zanetta and J.M. Matthieu, Purification and partial structural and functional characterization of mouse myelin/oligodendrocyte glycoprotein, $\mathrm{J} \mathrm{Neu}$ rochem 58 (1992), 1676-1682.

[2] C.C. Bernard, T.G. Johns, A. Slavin, M. Ichikawa, C. Ewing, J. Liu and J. Bettadapura, Myelin oligodendrocyte glycoprotein: a novel candidate autoantigen in multiple sclerosis, $\mathrm{J} \mathrm{Mol} \mathrm{Med}$ 75 (1997), 77-88.

[3] T. Berger, P. Rubner, F. Schautzer, R. Egg, H. Ulmer, I. Mayringer, E. Dilitz, F. Deisenhammer and M. Reindl, Antimyelin antibodies as a predictor of clinically definite multiple sclerosis after a first demyelinating event, $N$ Engl J Med 349 (2003), 139-145

[4] U. Brehm, S.J. Piddlesden, M.V. Gardinier and C. Linington, Epitope specificity of demyelinating monoclonal autoantibodies directed against the human myelin oligodendrocyte glycoprotein (MOG), J Neuroimmunol 97 (1999), 9-15.

[5] K.A. Brokstad, M. Page, H. Nyland and L.R. Haaheim, Autoantibodies to myelin basic protein are not present in the serum and CSF of MS patients, Acta Neurol Scand 89 (1994), 407-411.

[6] I. Catz and K.G. Warren, Intrathecal synthesis of autoantibodies to myelin basic protein in multiple sclerosis, Can. Neurol Sci 13 (1986), 21-24.

[7] E. Colombo, K. Banki, A.H. Tatum, J. Daucher, P. Ferrante, R.S. Murray, P.E. Phillips and A. Perl, Comparative analysis of antibody and cell-mediated autoimmunity to transaldolase and myelin basic protein in patients with multiple sclerosis, $J$ Clin Invest 99 (1997), 1238-1250.

[8] C.S. Clements, H.H. Reid, T. Beddoe, F.E. Tynan, M.A. Perugini, T.G. Johns, C.C. Bernard and J. Rossjohn, The crystal structure of myelin oligodendrocyte glycoprotein, a key autoantigen in multiple sclerosis, PNAS USA. 100 (2003), 11059-11064.

[9] J. Correale, M. de los Milagros Bassani Molinas, Oligoclonal bands and antibody responses in multiple sclerosis, J Neurol 249 (2002), 375-389.

[10] M.V. Gardinier, P. Amiguet, C. Linington and J.M. Matthieu, Myelin/oligodendrocyte glycoprotein is a unique member of the immunoglobulin superfamily, J Neurosci Res 33 (1992), $177-187$.

[11] C.P. Genain, B. Cannella, S.L. Hauser and C.S. Raine, Identification of autoantibodies associated with myelin damage in multiple sclerosis, Nat. Med. 5 (1999), 170-175.

[12] M.K. Gorny, Z. Wroblewska, D. Pleasure, S.L. Miller, A. Wajgt and H. Koprowski, CSF antibodies to myelin basic protein and oligodendrocytes in multiple sclerosis and other neurological diseases, Acta Neurol Scand 67 (1983), 338-347.

[13] C.G. Haase, J. Guggenmos, U. Brehm, M. Andersson, T. Olsson, M. Reindl, J.M. Schneidewind, U.K. Zettl, F. Heidenreich, T. Berger, H. Wekerle, R. Hohlfeld and C. Linington, The fine specificity of the myelin oligodendrocyte glycoprotein autoantibody response in patients with multiple sclero- 
sis and normal healthy controls, J Neuroimmunol 114 (2001), 220-225.

[14] N. Hellings, M. Baree, C. Verhoeven. M.B. D'hooghe, R. Medaer, C.C. Bernard, J. Raus and P. Stinissen, T-cell reactivity to multiple myelin antigens in multiple sclerosis patients and healthy controls, J Neurosci Res 63 (2001), 290-302.

[15] N. Hellings, J. Raus and P. Stinissen, Insights into the immunopathogenesis of multiple sclerosis, Immunol Res $\mathbf{2 5}$ (2002), 27-51.

[16] M. Hobom, M.K. Storch, R. Weissert, K. Maier, A. Radhakrishnan, B. Kramer, M. Bahr and R. Diem, Mechanisms and time course of neuronal degeneration in experimental autoimmune encephalomyelitis, Brain Pathol 14 (2004), 148-157.

[17] R. Hohlfeld, M. Kerschensteiner, C. Stadelmann, H. Lassmann and $\mathrm{H}$. Wekerle, The neuroprotective effect of inflammation: implications for the therapy of multiple sclerosis, $J$ Neuroimmunol 107 (2000), 161-166.

[18] T. Ichioka, K. Uobe, M. Stoskopf, Y. Kishimoto, G. Tennekoon and W.W. Tourtellotte, Antigalactocerebrosidase antibodies in human cerebrospinal fluid determined by enzyme-linked immunosorbent assay (ELISA), Neurochem Res 13 (1988), 203-207.

[19] A. Iglesias, J. Bauer, T. Litzenburger, A. Schubart and C. Linington, T cell and B cell responses to myelin oligodendrocyte glycoprotein in experimental autoimmune encephalomyelitis and multiple sclerosis, Glia 36 (2001), 220-234.

[20] A. Karni, R. Bakimer-Kleiner, O. Abramsky and A. BenNun, Elevated levels of antibody to myelin oligodendrocyte glycoprotein is not specific for patients with multiple sclerosis, Arch Neurol 56 (1999), 311-315.

[21] A. Kennel De March, M. De Bouwerie, M.N. Kolopp-Sarda, G.C. Faure, M.C. Bene and C.C. Bernard, Anti-myelin oligodendrocyte glycoprotein B-cell responses in multiple sclerosis, J Neuroimmunol 135 (2003), 117-125.

[22] M. Kerschensteiner, E. Gallmeier, L. Behrens, V.V. Leal, T. Misgeld, W.E. Klinkert, R. Kolbeck, E. Hoppe, R.L. OropezaWekerle, I. Bartke, C. Stadelmann, H. Lassmann, H. Wekerle and R. Hohlfeld, Activated human T cells, B cells, and monocytes produce brain-derived neurotrophic factor in vitro and in inflammatory brain lesions: a neuroprotective role of inflammation? J Exp Med 189 (1999), 865-870.

[23] K. Kimura, S.F. Hunter, M.S. Thollander, E.V. Loftus, L.J. Melton, P.C. O'Brien, M. Rodriguez and S.F. Phillips, Concurrence of inflammatory bowel disease and multiple sclerosis, Mayo Clinic Proc 75 (2000), 802-806.

[24] V. Lampasona, D. Franciotta, R. Furlan, S. Zanaboni, R. Fazio, E. Bonifacio, G. Comi and G. Martino, Similar low frequency of anti-MOG IgG and IgM in MS patients and healthy subjects, Neurology 62 (2004), 2092-2094.

[25] R. Lebar, C. Lubetzki, C. Vincent, P. Lombrail and J.M. Boutry, The $\mathrm{M}_{2}$ autoantigen of central nervous system myelin, a glycoprotein present in oligodendrocyte membrane, Clin Ex.p Immunol 66 (1986), 423-434.

[26] C. Linnington, M. Bradl, H. Lassmann, C. Brunner and K. Vaas, Augmentation of demyelination in rag acute allergic encephalomyelitis by circulating mouse monoclonal antibodies directed against a myelin/oligodendrocyte glycoprotein, Am J Pathol 130 (1988), 443-454.

[27] C. Linnington, M. Webb and P.L. Woodhams, A novel myelinassociated glycoprotein defined by a mouse monoclonal antibody, J Neuroimmunol 6 (1984), 387-396.

[28] C. Lucchinetti, W. Bruck, J. Parisi, B. Scheithauer, M. Ro- driguez and H. Lassmann, Heterogeneity of multiple sclerosis lesions: implications for the pathogenesis of demyelination, Ann Neurol 47 (2000), 707-717.

[29] R. Mantegazza, P. Cristaldini, P. Bernasconi, F. Baggi, R. Pedotti, I. Piccini, N. Mascoli, L.L. Mantia, C. Antozzi, O. Simoncini, F. Cornelio and C. Milanese, Anti-MOG autoantibodies in Italian multiple sclerosis patients: specificity, sensitivity and clinical association, Int Immunol 16 (2004), 559555.

[30] W.I. McDonald, A. Compston, G. Edan, D. Goodkin, H.P. Hartung, F.D. Lublin, H.F. McFarland, D.W. Paty, C.H. Polman, S.C. Reingold, M. Sandberg-Wollheim, W. Sibley. A. Thompson, S. van den Noort, B.Y. Weinshenker and J.S. Wolinsky, Recommended diagnostic criteria for multiple sclerosis: guidelines from the International Panel on the diagnosis of multiple sclerosis, Ann Neurol 50 (2001), 121-127.

[31] H. Neumann, Molecular mechanisms of axonal damage in inflammatory central nervous system diseases, Curr Opin Neurol 16 (2003), 267-273.

[32] K.C. O’Connor, T. Chitnis, D.E. Griffin, S. Piyasirisilp, A. Bar-Or, S. Khoury, K.W. Wucherpfennig and D.A. Hafler, Myelin basic protein-reactive autoantibodies in the serum and cerebrospinal fluid of multiple sclerosis patients are characterized by low-affinity interactions, J Neuroimmunol 136 (2003), $140-148$.

[33] T. Olsson, S. Baig, B. Hojeberg and H. Link, Antimyelin basic protein and antimyelin antibody-producing cells in multiple sclerosis, Ann Neurol 27 (1990), 132-136.

[34] H.S. Panitch, C.J. Hooper and K.P. Johnson, CSF antibody to myelin basic protein: measurement in patients with multiple sclerosis and subacute sclerosing panencephalitis, Arch Neurol 37 (1980), 206-209.

[35] D. Pham-Dinh, M.G. Mattei, J.L. Nussbaum, G. Roussel, P. Pontarotti, N. Roeckel, I.H. Mather, K. Artzt, K.F. Lindahl and A. Dautigny, Myelin/oligodendrocyte glycoprotein is a member of a subset of the immunoglobulin superfamily encoded within the major histocompatibility complex, PNAS USA 90 (1993), 7990-7994.

[36] C.S. Raine, B. Cannella, S.L. Hauser and C.P. Genain, Demyelination in primate autoimmune encephalomyelitis and acute multiple sclerosis lesions: a case for antigen-specific antibody mediation, Ann Neurol 46 (1999), 144-160.

[37] M. Schwartz, G. Moalem, R. Leibowitz-Amit, E. Yoles, F. Mor and I.R. Cohen, Beneficial immune activity after CNS injury: prospects for vaccination. Autoimmune T cells protect neurons from secondary degeneration after central nervous system axotomy, Nat Med 5 (1999), 49-55.

[38] N.J. Scolding, S. Frith, C. Linington, B.P. Morgan, A.K. Campbell and D.A. Compston, Myelin-oligodendrocyte glycoprotein (MOG) is a surface marker of oligodendrocyte maturation, J Neuroimmunol 22 (1989), 169-176.

[39] A. Seamons, A. Perchellet and J. Goverman, Immune tolerance to myelin proteins, Immunol Res 28 (2003), 201-221.

[40] M.K. Storch, A. Stefferl, U. Brehm, R. Weissert, E. Wallstrom, M. Kerschensteiner, T. Olsson, C. Linington and H. Lassmann, Autoimmunity to myelin oligodendrocyte glycoprotein in rats mimics the spectrum of multiple sclerosis pathology, Brain Pathol 8 (1998), 681-694.

[41] J.W. Terryberry, G. Thor and J.B. Peter, Autoantibodies in neurodegenerative diseases: antigen-specific frequencies and intrathecal analysis, Neurobiol Aging 19 (1998), 205-216. 


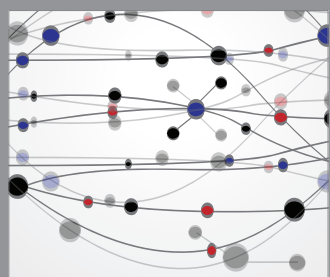

The Scientific World Journal
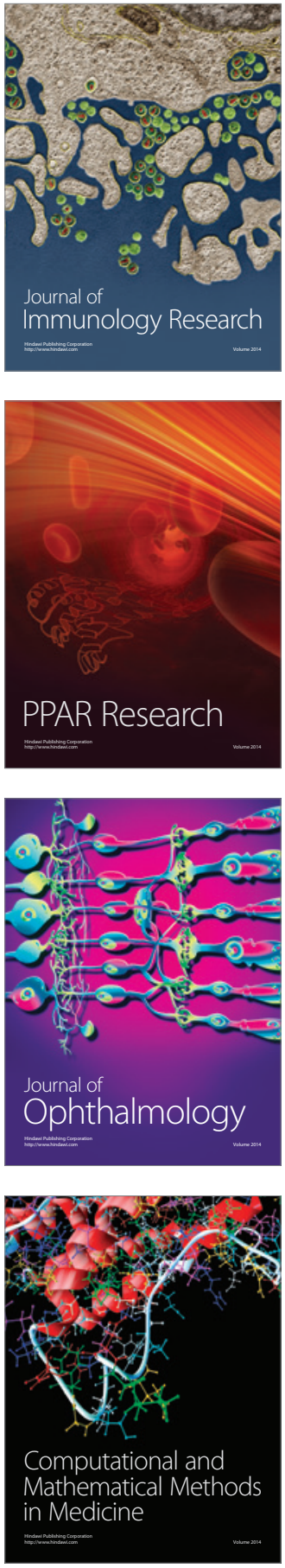

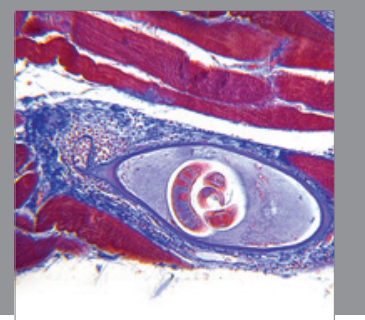

Gastroenterology

Research and Practice
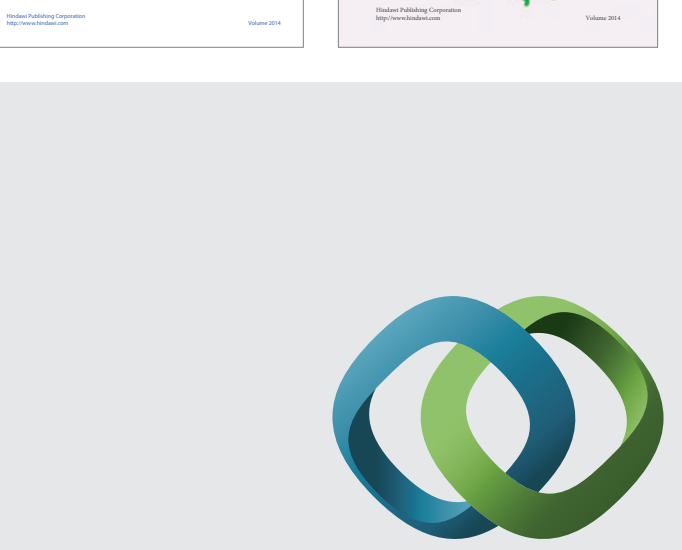

\section{Hindawi}

Submit your manuscripts at

http://www.hindawi.com
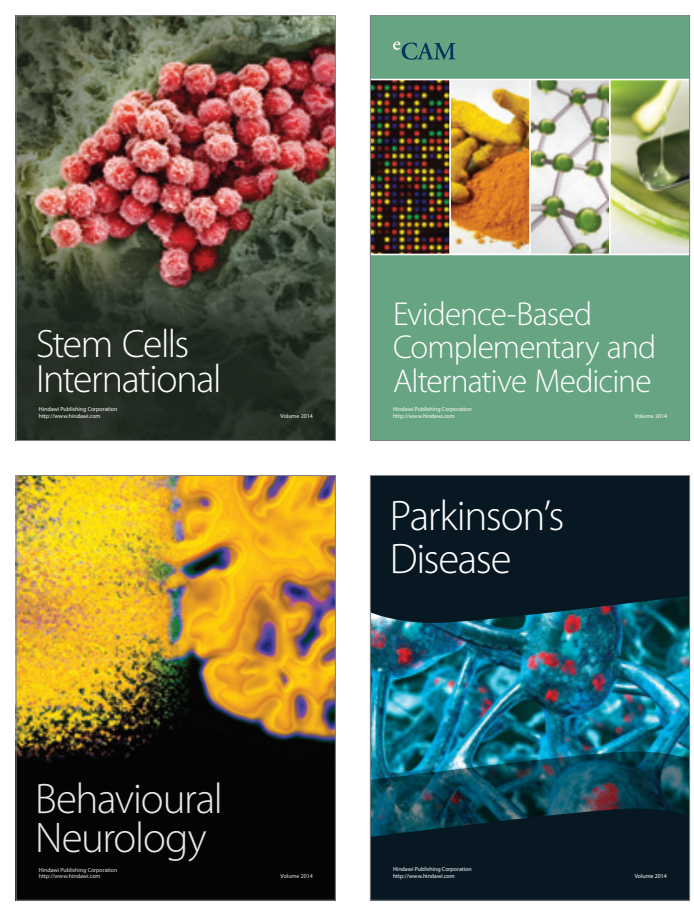

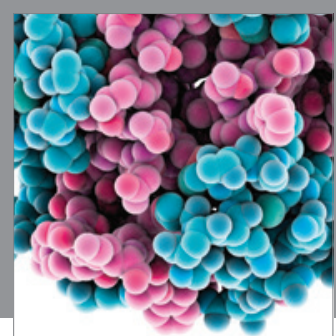

Journal of
Diabetes Research

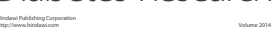

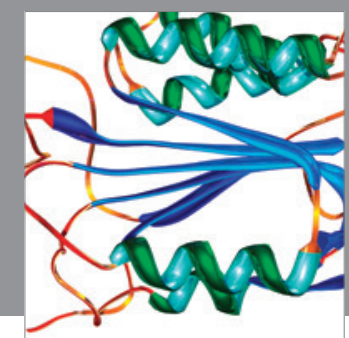

Disease Markers
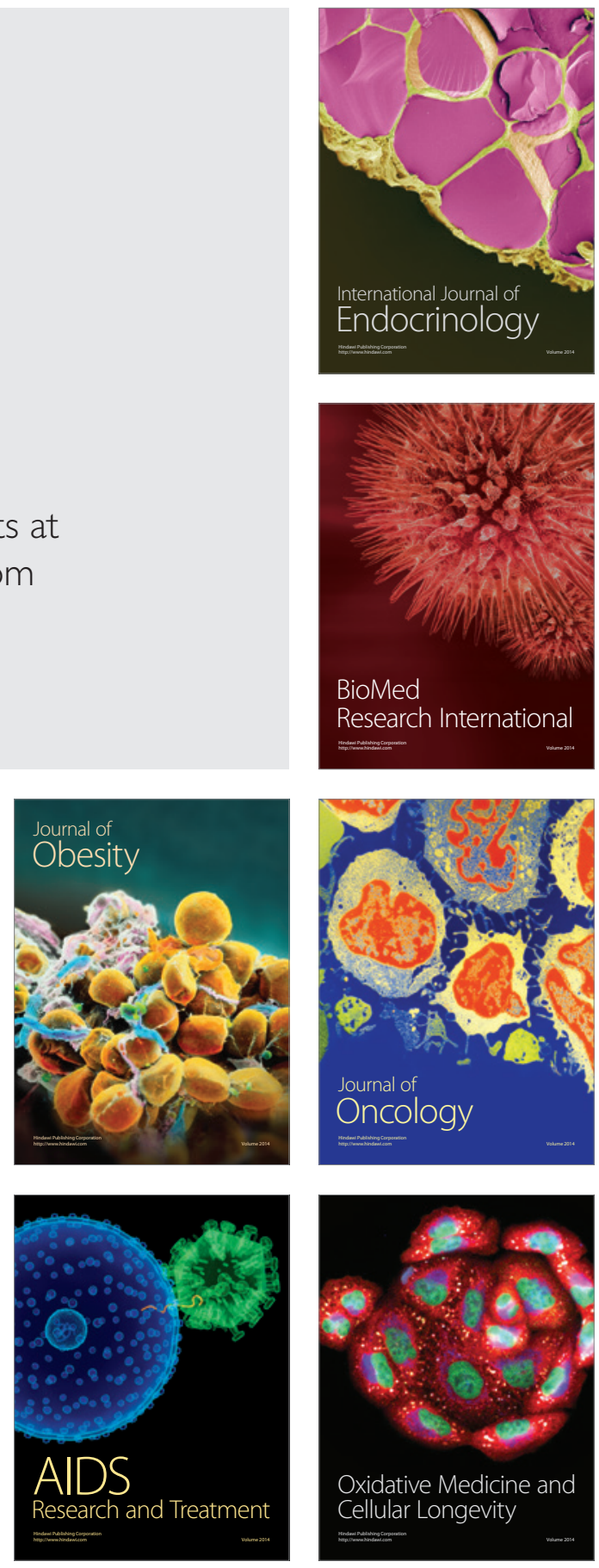